\title{
Separation, Identification, and Antioxidant Activity of Polyphenols from Lotus Seed Epicarp
}

\author{
Zhili Ma ${ }^{1}$, Yi Huang ${ }^{2}$, Wen Huang ${ }^{2}$, Xi Feng ${ }^{3}$, Fang Yang ${ }^{1, *}$ and Deyuan Li ${ }^{1, *}$ \\ 1 School of Laboratory Medicine, Hubei University of Chinese Medicine, Wuhan, Hubei 430065, China; \\ mazhilitoo@hotmail.com \\ 2 College of Food Science and Technology, Huazhong Agricultural University, Wuhan, Hubei 430070, China; \\ mariahuang@webmail.hzau.edu.cn (Y.H.); huangwen@mail.hzau.edu.cn (W.H.) \\ 3 Department of Nutrition, Food Science and Packaging, California State University, San Jose, CA 95192, USA; \\ xi.feng@sjsu.edu \\ * Correspondence: fangy521@hbtcm.edu.cn (F.Y.); lideyuan66@sina.com (D.L.); Tel.: +86-13986047925
}

Academic Editor: Matteo Scampicchio

Received: 29 September 2019; Accepted: 4 November 2019; Published: 5 November 2019

\begin{abstract}
Lotus seed epicarp, the main by-product of lotus seed processing, is abundant in polyphenols. In this study, polyphenols in lotus seed epicarp were separated by Sephadex LH-20 gel filtration chromatography to yield Fraction-I (F-I), Fraction-II (F-II), and Fraction-III (F-III). The polyphenol compounds in the three fractions were identified by UPLC-MI-TOF-MS. Six kinds of polyphenol compounds including cyanidin-3-O-glucoside, procyanidin trimer, and phlorizin were identified in F-I, and prodelphinidin dimer B, procyanidin dimer, and quercetin hexoside isomer were found in F-II. However, there was only procyanidin dimer identified in F-III. The in vitro antioxidant activities of the three fractions were also investigated. We found F-I, F-II, and F-III had strong potential antioxidant activities in the order of F-III > F-II > F-I. Our results suggested that polyphenols from lotus seed epicarp might be suitable for use as a potential food additive.
\end{abstract}

Keywords: lotus seed epicarp; polyphenols; separation; identification; antioxidant activity

\section{Introduction}

Lotus (Nelumbo nucifera Gaertn.) is an important aquatic economic crop in China, and it has been widely cultivated in Asia [1,2]. Almost every part of lotus (roots, leaves, flowers, and seeds) not only can be used as a food-stuff, but also have multiple medicinal functions [3]. In China, lotus leaves and seeds are publicly identified as both food and medicine resources. There is much research concerned with lotus leaves and seeds [4-7]. It has been reported that the extract from lotus leaves and seeds have multiple bioactivities, such as being anti-oxidant [8,9], anti-inflammatory [10], immuno-modulatory [11], and anti-obesity [12] etc. The bioactivities of lotus are due to the functional components in lotus including polysaccharides, polyphenols, flavonoids etc.

From the view of converting food waste into by-products, several kinds of bioactive flavonoid, proanthocyanidin, and phenolic compounds have been extracted and identified from the receptaculum nelumbinis [13-15]. As an inedible part of lotus, lotus seed epicarp also has attracted additional attention. Lotus seed epicarp, the main by-product of lotus seed processing, is also abundant in polyphenols and worthy to be used as a functional food. Lotus seed epicarp extract has been used as a potential antioxidant and anti-obesity additive in Chinese Cantonese Sausage, which was the first use of lotus seed epicarp extract in meat product [16]. Liu, et al. [17] reported that polyphenols from lotus seed epicarp at three different ripening stages have good anti-radical abilities, and they identified some phenolic compounds from lotus seed epicarp. Recently, Liu, et al. [18] found that the anti-radical activity of polyphenols from lotus seed epicarp increases by probiotic bacteria bioconversion. Yan, et al. [19] 
reported that polyphenols from lotus seed epicarp have antiproliferation ability on human hepatoma G2 (HepG2) cells. However, little is known about the purification and identification of the key bioactive polyphenols from lotus seed epicarp.

The aims of this study were to separate polyphenols from lotus seed epicarp into different fractions, characterize the phenolic profiles of polyphenol fractions by UPLC-MI-TOF-MS. The antioxidant activities of polyphenol fractions were also determined.

\section{Results and Discussion}

\subsection{Purification and Identification of Lotus Seed Epicarp Polyphenols}

As shown in Figure 1, the lotus seed epicarp polyphenols obtained after AB-8 macroporous resin were then separated with a Sephadex LH-20 gel filtration chromatography and three fractions (Fraction-I (F-I), Fraction-II (F-II), and Fraction-III (F-III)) were separately collected. In order to figure out the structure of the main polyphenols in the three fractions, UPLC-MS/MS was employed to identify the polyphenol compounds.

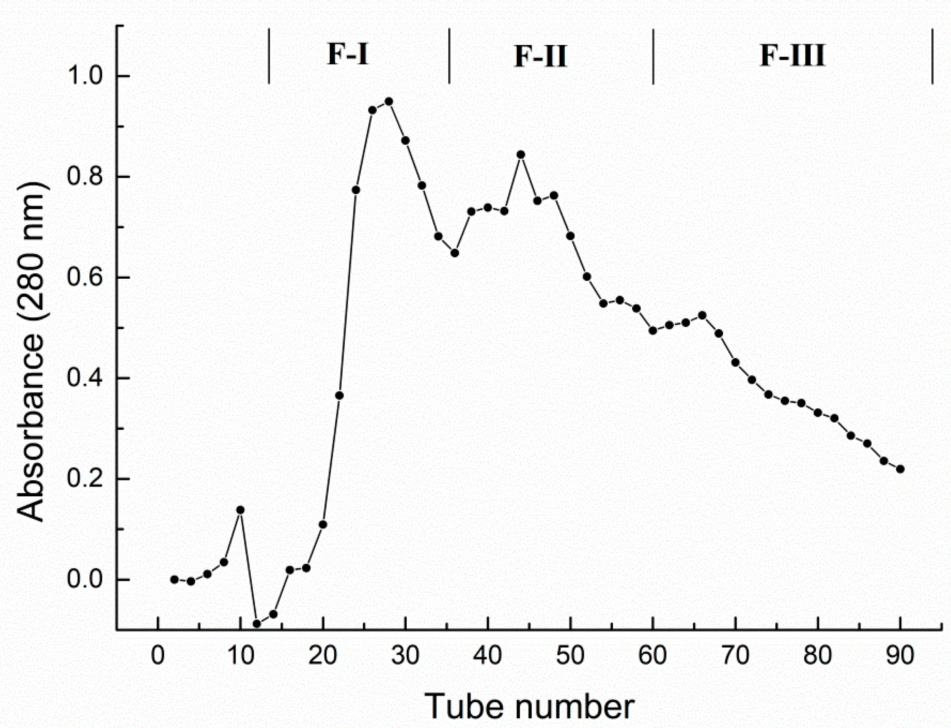

Figure 1. Separation of polyphenols from lotus seed epicarp by Sephadex LH-20 gel column into Fraction-I (F-I), Fraction-II (F-II), and Fraction-III (F-III).

A total of six phenolic compounds were identified in the three selected fractions. However, Liu, Ma, Ibrahim, Li, Yang and Huang [17] identified four kinds of polyphenols from lotus seed epicarp, and Yan, Luo, Cong, Zhang, Ma and Duan [19] found eight kinds of polyphenols from fresh lotus seed epicarp. These differences may be caused by varied purification and identification methods. Three kinds of polyphenol compounds were identified from the sample of F-I, which were cyanidin-3-O-glucoside, procyanidin trimer and phlorizin. As shown in Table 1, compound $1(\mathrm{RT}=4.68 \mathrm{~min})$ showed a molecular ion $\left([\mathrm{M}-\mathrm{H}]^{-}\right)$at mass/charge ratio $(\mathrm{m} / \mathrm{z})$ of 449.1087 . The main fragment at $\mathrm{m} / \mathrm{z}$ of 287.0558 was identified as cyanidin by the neutral loss of a dehydrated glucose from compound $\mathbf{1}$ [20]. The result was consistent with the report of cyanidin-3-O-glucoside by Tian, et al. [21]. Compound 2 showed the molecular ion $\left([\mathrm{M}-\mathrm{H}]^{-}\right)$at $\mathrm{m} / \mathrm{z}$ of 865.1975 and two fragments at $\mathrm{m} / \mathrm{z}$ of $449.1088,287.0557$, which was the result of its direct cleavage of the inter flavanic bond, and was identified as the procyanidin trimer [22]. Compound $3(\mathrm{RT}=7.75 \mathrm{~min})$ showed a molecular ion $\left([\mathrm{M}-\mathrm{H}]^{-}\right)$at $\mathrm{m} / \mathrm{z}$ of 435.1293 , and the main fragment at $\mathrm{m} / \mathrm{z}$ of 273.0761 was phloretin by the loss of glucose from compound 3 . Therefore, compound 3 was identified as phlorizin [23]. 
Table 1. Identification of compounds in three polyphenol fractions from lotus seed epicarp.

\begin{tabular}{|c|c|c|c|c|c|c|}
\hline Compound & Fraction & $\begin{array}{l}\text { Retention } \\
\text { Time (min) }\end{array}$ & $\begin{array}{c}{[\mathbf{M}-\mathbf{H}]^{-}} \\
(\mathrm{m} / \mathrm{z})\end{array}$ & $\begin{array}{c}\text { Typical } \\
\text { MS/MS } \\
\text { Ions (m/z) }\end{array}$ & Formula & Identification \\
\hline 1 & F-I & 4.68 & 449.1087 & 287.0558 & $\mathrm{C}_{21} \mathrm{H}_{21} \mathrm{O}_{11}$ & Cyanidin-3-O-glucoside \\
\hline 2 & F-I & 5.15 & 865.1975 & $\begin{array}{l}449.1088 \\
287.0557\end{array}$ & $\mathrm{C}_{45} \mathrm{H}_{38} \mathrm{O}_{18}$ & Procyanidin trimer \\
\hline 3 & F-I & 7.75 & 435.1293 & 273.0761 & $\mathrm{C}_{21} \mathrm{H}_{24} \mathrm{O}_{10}$ & Phlorizin \\
\hline 4 & F-II & 2.56 & 593.1306 & $\begin{array}{l}407.0770 \\
289.0715\end{array}$ & $\mathrm{C}_{30} \mathrm{H}_{26} \mathrm{O}_{13}$ & Prodelphinidin dimer B \\
\hline 5 & F-II & 4.53 & 577.1346 & $\begin{array}{l}407.0770 \\
289.0715\end{array}$ & $\mathrm{C}_{30} \mathrm{H}_{26} \mathrm{O}_{12}$ & Procyanidin dimer \\
\hline 6 & F-II & 6.23 & 463.0875 & $\begin{array}{l}301.0336 \\
300.0268\end{array}$ & $\mathrm{C}_{21} \mathrm{H}_{20} \mathrm{O}_{12}$ & $\begin{array}{l}\text { Quercetin hexoside } \\
\text { isomer }\end{array}$ \\
\hline 7 & F-III & 4.91 & 577.1347 & $\begin{array}{l}407.0770 \\
289.0711\end{array}$ & $\mathrm{C}_{30} \mathrm{H}_{26} \mathrm{O}_{12}$ & Procyanidin dimer \\
\hline 8 & F-III & 5.42 & 577.1347 & $\begin{array}{l}407.0770 \\
289.0713\end{array}$ & $\mathrm{C}_{30} \mathrm{H}_{26} \mathrm{O}_{12}$ & Procyanidin dimer \\
\hline
\end{tabular}

Three major polyphenol compounds including prodelphinidin dimer B, procyanidin dimer, and quercetin hexoside isomer were identified from F-II. According to Table 1, compound 4 (RT = $2.56 \mathrm{~min}$ ) showed the molecular ion $\left([\mathrm{M}-\mathrm{H}]^{-}\right)$at $\mathrm{m} / \mathrm{z}$ of 593.1306 and was a monomeric unit of catechin and gallocatechin. The fragment ion $\mathrm{m} / \mathrm{z} 407.0770$ was due to a retro-Diels-Alder (RDA) fission of ring C and further elimination of a molecule of water, while the ion $\mathrm{m} / \mathrm{z} 289.0715$ was after a quinone-methide $(\mathrm{QM})$ cleavage of the interflavan bond $[24,25]$. Compound $5(\mathrm{RT}=4.53)$ showed a molecular ion $\left([\mathrm{M}-\mathrm{H}]^{-}\right)$at $\mathrm{m} / \mathrm{z}$ of 577.1346 was identified as a procyanidin dimer which was a monomeric unit of catechin and epicatechin [26,27]. The produced two fragments at $\mathrm{m} / \mathrm{z}$ of 407.07732 and 289.07161 were the same with that of prodelphinidin dimer B [25]. Compound $6(\mathrm{RT}=4.53)$ had a ion $[\mathrm{M}-\mathrm{H}]^{-} \mathrm{at} \mathrm{m} / \mathrm{z}$ 463.0875 and yielded fragment ions at $\mathrm{m} / \mathrm{z} 301.0336$ and 300.0268 corresponding to losses of a hexose moiety [28]. Therefore, compound 6 was assigned as quercetin-3-O-glucoside [27].

As shown in Table 1, the main polyphenol compound in F-III was procyanidin dimer. Both compound $7(\mathrm{RT}=4.91)$ and compound $8(\mathrm{RT}=5.42)$ with the molecular ion $\left([\mathrm{M}-\mathrm{H}]^{-}\right)$at $\mathrm{m} / \mathrm{z}$ of 577.1347 were identified as a procyanidin dimer.

\subsection{Antioxidant Activity}

\subsection{1. $\mathrm{ABTS}^{+}$Radical Scavenging Ability of Polyphenol Fractions}

The 2,2' -azino-bis-3-ethylbenzthiazoline-6-sulphonic acid $\left(\mathrm{ABTS}^{+}\right)$radical scavenging abilities of the three polyphenol fractions from lotus seed epicarp (F-I, F-II, and F-III) are shown in Figure 2. Compared to $\mathrm{V}_{c}$, the $\mathrm{ABTS}^{+}$radical scavenging capacities of the three polyphenol fractions were higher than that of $\mathrm{V}_{\mathrm{c}}(p<0.05)$. The $\mathrm{IC}_{50}$ values of F-I, F-II, and F-III were $5.04,4.22$, and $3.96 \mu \mathrm{g} / \mathrm{mL}$, respectively. The result was lower than that of purified polyphenols from lotus seed epicarp $(45.27 \mu \mathrm{g} / \mathrm{mL})$ reported by Liu, Ma, Ibrahim, Li, Yang and Huang [17]. The better ABTS ${ }^{+}$radical scavenging capacities of our polyphenol fractions might be due to the synergistic effect of various polyphenols. Generally, the $\mathrm{ABTS}^{+}$radical scavenging capacities increased in the order of: F-III $>$F-II $>$F-I. Furthermore, at the concentration of $10 \mu \mathrm{g} / \mathrm{mL}$, the ABTS ${ }^{+}$radical scavenging rates of F-I, F-II, and F-III were $89.16 \%$, $94.60 \%$, and $96.38 \%$, respectively. Our results indicate that the three polyphenol fractions from lotus seed epicarp had potential anti-radical activity on the $\mathrm{ABTS}^{+}$radical. 


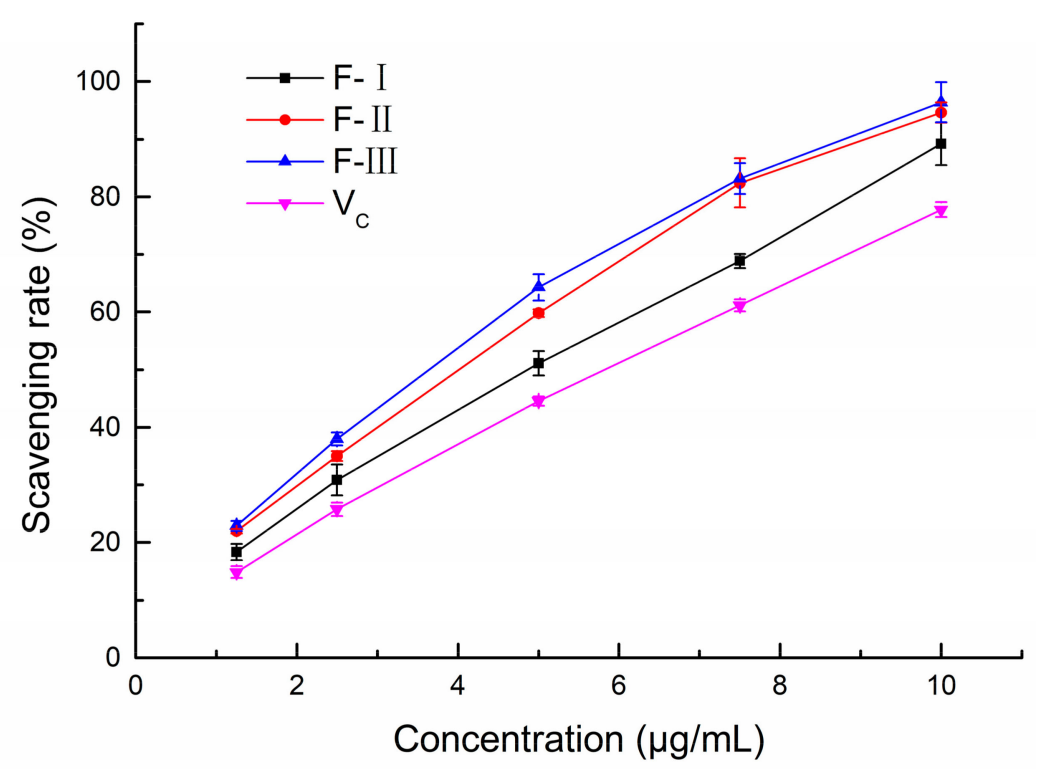

Figure 2. The capacities of three polyphenol fractions and vitamin C on 2,2'-azino-bis-3ethylbenzthiazoline-6-sulphonic acid $\left(\mathrm{ABTS}^{+}\right)$radicals.

\subsubsection{DPPH radical scavenging ability of polyphenol fractions}

The 1,1-diphenyl-2-picryl-hydrazyl (DPPH) radical scavenging abilities of F-I, F-II, F-III and $\mathrm{V}_{\mathrm{c}}$ are shown in Figure 3. The DPPH radical scavenging rates of the three polyphenol fractions firstly increased to the peak rate at the concentration of $15 \mu \mathrm{g} / \mathrm{mL}$, and then the scavenging rates decreased steadily. F-III had a better anti-radical activity on DPPH than that of $\mathrm{V}_{\mathrm{c}}$, whereas the DPPH radical scavenging rates of F-I and F-II were lower than that of $\mathrm{V}_{\mathrm{c}}$ at the same concentration. The $\mathrm{IC}_{50}$ values of F-I, F-II, and F-III were 3.50, 4.75, and $2.26 \mu \mathrm{g} / \mathrm{mL}$, respectively. The DPPH radical scavenging activity increased in the order of: F-III > F-I > F-II. Moreover, at a concentration of $15 \mu \mathrm{g} / \mathrm{mL}$, the DPPH radical scavenging rates of F-I, F-II, and F-III reached $93.90 \%, 94.11 \%$, and $95.03 \%$, respectively. Our results thus indicated that the three polyphenol fractions from lotus seed epicarp had positive scavenging capacities on the DPPH radical.

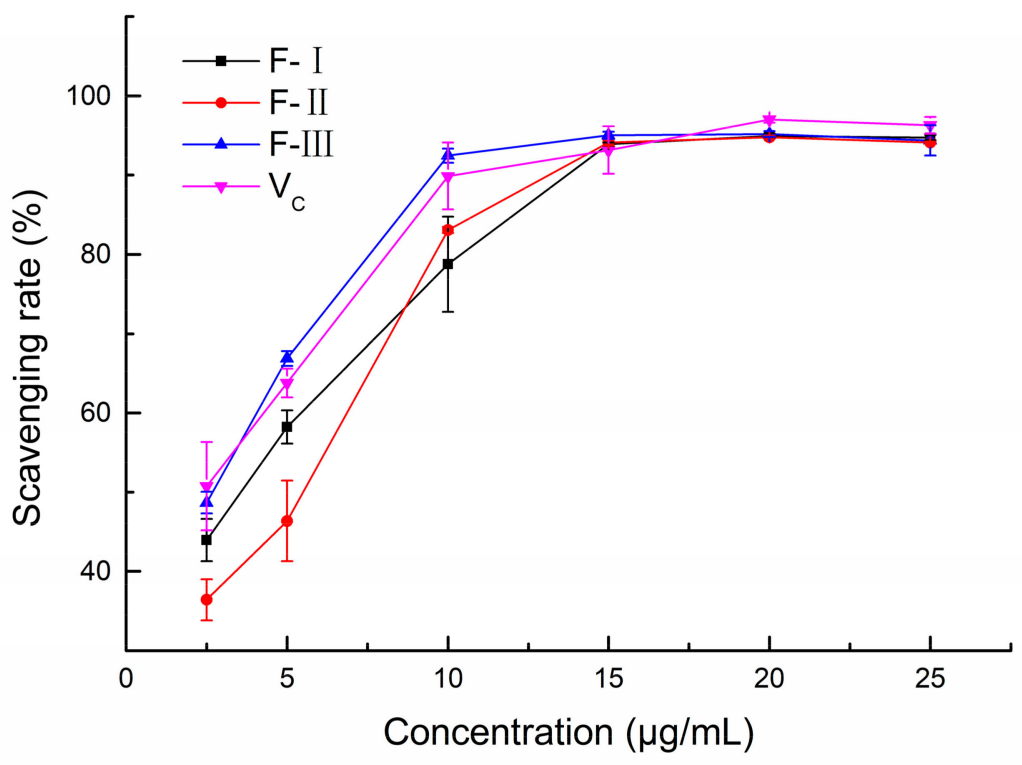

Figure 3. The capacities of three polyphenol fractions and vitamin C on 1,1-diphenyl-2-picryl-hydrazyl (DPPH) free radicals. 


\subsubsection{FRAP of Polyphenol Fractions}

The ferric ion reducing antioxidant power (FRAP) of the three polyphenol fractions are shown in Figure 4. The FRAP values of F-I, F-II, and F-III were $1.41,1.70$, and $2.00 \mathrm{mMFe}^{2+} / \mu \mathrm{g}$, respectively. The results indicated that the FRAP of the polyphenol fractions increased in the order of: F-III $>$ F-II $>$ F-I $(p<0.05)$. The FRAP values were higher than other reported polyphenols [29,30]. Our results suggest that three polyphenol fractions from lotus seed epicarp had high FRAP levels.

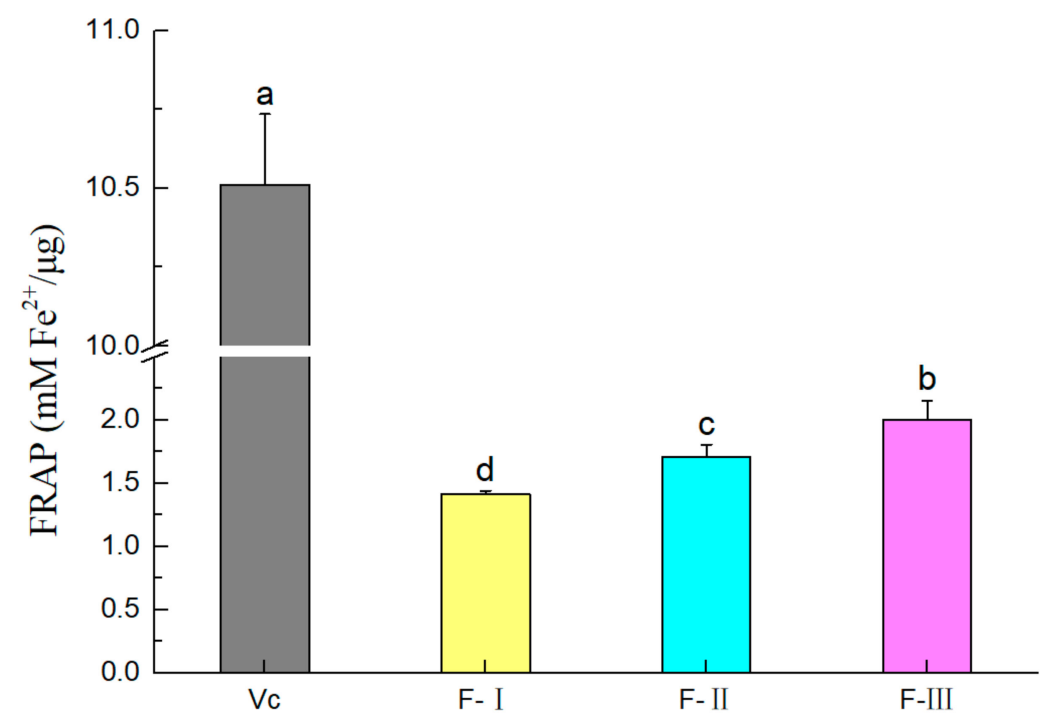

Figure 4. The ferric ion reducing antioxidant power (FRAP) abilities of three polyphenol fractions and vitamin C. Different letters (a-d) indicate significant differences $(p<0.05)$.

The antioxidant activities of polyphenols from lotus seed epicarp were measured using FRAP assay as well as DPPH and $\mathrm{ABTS}^{+}$radicals scavenging methods. These methods were widely used to measure antioxidant activity of natural compounds in vitro [31]. These tests have indicated different mechanisms of antioxidant action. The ABTS ${ }^{+}$assay is superior to the DPPH assay when applied to samples containing hydrophilic, lipophilic, and highly pigmented antioxidant compounds [32]. We found that the three polyphenol fractions from lotus seed epicarp had strong antioxidant activities in vitro. Similar results were also reported about sweet potato leaf polyphenols [33]. In addition, there were significant differences among the three polyphenol fractions in the antioxidant activity assays. The F-III had the highest antioxidant activity, which may have been caused by the higher level of procyanidin dimer in F-III. Similar results have also been reported in that the procyanidin dimer is the most active free radical scavenging polyphenol [34,35].

\section{Materials and Methods}

\subsection{Materials and Chemicals}

Dried lotus seed epicarp (at full ripening stage with a water content of 10.3\%) was from a local farm in HuNan province and then ground into powder, sieved through 100 meshes, and stored at $-20{ }^{\circ} \mathrm{C}$ for further study.

AB-8 macroporous resin was purchased from Solarbio Co. (Beijing, China). Sephadex LH-20 was purchased from GE Healthcare Co. (Uppsala, Sweden). DPPH radical, ABTS ${ }^{+}$radical, trolox and Folin-Ciocalteu reagent were purchased from Shanghai yuanye Bio-Technology Co., Ltd (Shanghai, China). Analytically pure anhydrous sodium carbonate, ascorbic acid, gallic acid monohydrate, sodium chloride, and potassium persulfate were obtained from Sinopharm Chemical Reagent Co., Ltd. (Beijing, China). Acetonitrile, methanol, and formic acid of chromatographic grade were purchased from Tedia (Shanghai, China). 


\subsection{Preparation of Crude Polyphenols from Lotus Seed Epicarp}

Lotus seed epicarp powder was soaked in $60 \%$ ethanol solution at $1: 20$ ratio $(\mathrm{w} / \mathrm{v})$ in a $50{ }^{\circ} \mathrm{C}$ water bath for $90 \mathrm{~min}$. The resulting solution was concentrated and lyophilized for further tests.

\subsection{Determination of Total Phenolic Contents}

Total phenolic content (TPC) was measured by a reported method [36]. Crude polyphenols from lotus seed epicarp was dissolved in $\mathrm{ddH}_{2} \mathrm{O}$ to a concentration of $1 \mathrm{mg} / \mathrm{mL}$. Gallic acid standards or samples $(20 \mu \mathrm{L})$ were incubated at room temperature for $1 \mathrm{~min}$ with $100 \mu \mathrm{L}$ of 10 -fold diluted Folin-Ciocalteu reagent in 96-well plates followed by reaction with $80 \mu \mathrm{L}$ of $75 \mathrm{~g} / \mathrm{L} \mathrm{Na}_{2} \mathrm{CO}_{3}$ for $30 \mathrm{~min}$ and then absorbance at $765 \mathrm{~nm}$ was determined. All samples were measured in triplicate.

\subsection{Gel Filtration System Purification of Lotus Seed Epicarp Polyphenols}

Crude polyphenols from lotus seed epicarp was dissolved in $\mathrm{ddH}_{2} \mathrm{O}$ to a concentration of $5 \mathrm{mg} / \mathrm{mL}$. After centrifugation at 10,000 $\mathrm{g}$ for $5 \mathrm{~min}$, the supernatant was applied to a column of AB-8 macroporous resin. The column was eluted with $\mathrm{ddH}_{2} \mathrm{O}$ as mobile phase for $5 \mathrm{BV}$, and then followed by elution with $50 \%$ ethanol solution at a flow of $2 \mathrm{~mL} / \mathrm{min}$. The effluent was collected and subsequently dried with a rotary evaporator and lyophilizer.

The resulting purified polyphenols were loaded onto Sephadex LH-20 gel filtration chromatography column as described by Liu, Ma, Ibrahim, Li, Yang and Huang [17]. In short, the polyphenols were dissolved in methanol to a concentration of $50 \mathrm{mg} / \mathrm{mL}$ and centrifuged at 12,000 $\mathrm{g}$ for $5 \mathrm{~min}$, and then the supernatant was separated with a Sephadex LH-20 gel filtration chromatography column which was eluted with methanol at a flow of $0.5 \mathrm{~mL} / \mathrm{min}$. Each fraction of $8 \mathrm{~mL}$ was collected. Elution curves were obtained by measuring absorbance at $280 \mathrm{~nm}$ using an on-line spectrophotometer. The three fractions were collected and further analyzed by ultra performance liquid chromatography tandem mass spectrometry (UPLC-MS).

\subsection{UPLC-MS Analysis of Lotus Seed Epicarp Polyphenols}

For RP-HPLC separations a Waters 2690 system (Waters Corporation, Milford, USA) equipped with an automatic sample injector was used. Separations were performed at $0.4 \mathrm{~mL} / \mathrm{min}$ with eluent A consisted of $0.1 \%$ acetic acid in milli-Q water $(v / v)$; eluent $B$ of acetonitrile. The sample was filtered through a $0.22 \mathrm{~mm}$ syringe filter and injected into Acquity UPLC BEH C18 $(2.1 \mathrm{~mm} \times 100 \mathrm{~mm}, 1.7$ $\mu \mathrm{m})$ column. LC/UV traces were recorded on-line with a Waters 2690 PDA detector with detection at $280 \mathrm{~nm}$. The elution program were as follows: 0-8 $\mathrm{min}, 5 \% \mathrm{~B}-35 \% \mathrm{~B}, 8-9 \mathrm{~min}, 35 \% \mathrm{~B}-50 \% \mathrm{~B}, 9-11 \mathrm{~min}$, $50 \%-80 \%$ B , 11-12 min, $80 \%$ B-5\% B. Mass spectrometry conditions: $\mathrm{ESI}^{-}$ion source, spectra were recorded over the mass/charge $(\mathrm{m} / \mathrm{z})$ range $50-1000$; capillary voltage: $2.5 \mathrm{kV}$, ion source temperature: $135^{\circ} \mathrm{C}$, solvent removal temperature: $350{ }^{\circ} \mathrm{C}$, solvent removal gas velocity: $600 \mathrm{~L} / \mathrm{h}$, cone hole gas flow rate: $50 \mathrm{~L} / \mathrm{h}$, collision energy: 20 30 eV. Capillary temperature was $365^{\circ} \mathrm{C}$, and pressure of ESI nebulizing gas $\left(\mathrm{N}_{2}\right)$ was $275.79 \mathrm{kPa}(40 \mathrm{psi})$; flow rate of drying gas $\left(\mathrm{N}_{2}\right)$ was $10.00 \mathrm{~L} / \mathrm{min}$.

\subsection{Antioxidant Assay of Lotus Seed Epicarp Polyphenols}

\subsubsection{DPPH Radical Scavenging Activity}

The capacity of lotus seed epicarp polyphenols (LSEP) purified by Sephadex LH-20 to scavenge DPPH free radicals was assessed as described by Chen, Ma and Kitts [36]. LSEP purified by Sephadex LH-20 were dissolved in $\mathrm{ddH}_{2} \mathrm{O}$ and diluted in methanol to $100 \mu \mathrm{g} / \mathrm{mL}$. Samples were incubated with $0.1 \mathrm{mM}$ DPPH in the final volume of $200 \mu \mathrm{L}$ at room temperature for $10 \mathrm{~min}$ in darkness and then absorbance at $519 \mathrm{~nm}$ was determined. $\mathrm{V}_{\mathrm{c}}$ was used as standard. The percentage inhibition of the DPPH free radical was calculated as $\%$ Inhibition $=\left(A_{c}-A_{s}\right) /\left(A_{c}-A_{b}\right) \times 100$, where $A_{c}=$ absorbance of $0.1 \mathrm{mM}$ DPPH alone in methanol, $\mathrm{A}_{\mathrm{s}}=$ absorbance of $0.1 \mathrm{mM}$ DPPH with sample in methanol, 
$\mathrm{A}_{\mathrm{b}}=$ absorbance of methanol solvent in absence of DPPH and sample. The $\mathrm{IC}_{50}$ values were calculated using OriginPro software (OriginLab Corporation, Northampton, MA, USA).

\subsection{2. $\mathrm{ABTS}^{+}$Radical Scavenging Activity}

Assays of ABTS proceeded essentially as described by Chen et al. [36]. ABTS ( $5 \mathrm{~mL}, 7 \mathrm{mM}$ ) was mixed with $\mathrm{K}_{2} \mathrm{~S}_{2} \mathrm{O}_{8}(88 \mu \mathrm{L}$ of $140 \mathrm{mM})$ overnight at room temperature in the dark. The stock ABTS solution $(0.6 \mathrm{~mL})$ was diluted with $\mathrm{ddH}_{2} \mathrm{O}(40 \mathrm{~mL})$ and absorbance adjusted to 0.7 at $734 \mathrm{~nm}$ to make the ABTS working solution. The samples were prepared as the methods mentioned above. Samples of $20 \mu \mathrm{L}$ in total were reacted with ABTS working solution $(180 \mu \mathrm{L})$ at room temperature in darkness for $10 \mathrm{~min}$, before recording absorbance readings taken at $734 \mathrm{~nm}$ by spectrophotometry. $\mathrm{V}_{\mathrm{c}}$ was used as standard. The percentage inhibition of the $\mathrm{ABTS}^{+}$radical was calculated as $\%$ Inhibition $=$ $\left(A_{c}-A_{s}\right) /\left(A_{c}-A_{b}\right) \times 100$, where $A_{c}=$ absorbance of ABTS $^{+}$alone in methanol, $A_{s}=$ absorbance of ABTS $^{+}$ with sample in methanol, $A_{b}=$ absorbance of methanol solvent in absence of ABTS $^{+}$and sample. The $\mathrm{IC}_{50}$ values were calculated using OriginPro software (OriginLab Corporation, Northampton, MA, USA).

\subsubsection{Ferric Ion Reducing Antioxidant Power (FRAP) Assay}

The FRAP was evaluated using the reported method [37,38]. In brief, the FRAP working solution was prepared to mix acetate buffer ( $\mathrm{pH} 3.6,300 \mathrm{mM}$ ), 2,4,6-tris (2-pyridyl)-s-triazime (TPTZ) solution (10 $\mathrm{mM})$ and $\mathrm{FeCl}_{3}$ solution $(20 \mathrm{mM})$ with a volume ratio 10:1:1. Afterwards, $5 \mu \mathrm{L}$ sample solution and 180 $\mu \mathrm{L}$ FRAP working solution was mixed with reaction at room temperature for $6 \mathrm{~min}$. The absorbance was determined at $593 \mathrm{~nm}$. Different concentrations of $\mathrm{FeSO}_{4}$ were used as standards. The concentration of $\mathrm{FeSO}_{4}\left(\mathrm{mM} \mathrm{Fe}^{2+} / \mu \mathrm{g}\right)$ was indirectly expressed as with equivalent antioxidant activity of sample.

\subsection{Statistical Analysis}

The result was expressed as mean values and standard deviation (SD). The variance was determined by the one-way analysis of variance (ANOVA) and differences between the samples were measured by Duncan's test (0.05).

\section{Conclusions}

In this study, we separated polyphenols from lotus seed epicarp into three fractions-F-I, F-II, and F-III. Six kinds of polyphenol compounds in the three fractions were identified by UPLC-MI-TOF-MS. Cyanidin-3-O-glucoside, procyanidin trimer, and phlorizin were identified in F-I, prodelphinidin dimer B, procyanidin dimer, and quercetin hexoside isomer were found in F-II, whereas only procyanidin dimer was identified in F-III. We found that the three polyphenol fractions from lotus seed epicarp had strong FRAP values as well as positive scavenging abilities against DPPH and ABTS radicals. Moreover, F-III had the best antioxidant activity among the three polyphenol fractions. The polyphenols from lotus seed epicarp might be a good candidate as a natural food additive. However, the application of polyphenols from lotus seed epicarp in food preservation remains to be further studied.

Author Contributions: Z.M. designed the experiments, analyzed the data, and wrote the paper; Y.H. performed the HPLC analysis; Z.M., X.F., F.Y., and D.L. wrote the paper; Z.M. and W.H. analyzed the data.

Acknowledgments: The authors greatly appreciate the Scientific Research Plan of Hubei Provincial Department of Education (No. Q20182002).

Conflicts of Interest: The authors declare no conflict of interest. 


\section{References}

1. Zhang, L.; Tu, Z.-C.; Wang, H.; Kou, Y.; Wen, Q.-H.; Fu, Z.-F.; Chang, H.-X. Response surface optimization and physicochemical properties of polysaccharides from Nelumbo nucifera leaves. Int. J. Biol. Macromol. 2015, 74, 103-110. [CrossRef] [PubMed]

2. Karki, R.; Jung, M.-A.; Kim, K.-J.; Kim, D.-W. Inhibitory Effect of Nelumbo nucifera (Gaertn.) on the Development of Atopic Dermatitis-Like Skin Lesions in NC/Nga Mice. Evid. -Based Complementary Altern. Med. 2012, 2012, 7. [CrossRef] [PubMed]

3. Limwachiranon, J.; Huang, H.; Shi, Z.; Li, L.; Luo, Z. Lotus Flavonoids and Phenolic Acids: Health Promotion and Safe Consumption Dosages. Compr. Rev. Food Sci. Food Saf. 2018, 17, 458-471. [CrossRef]

4. Hu, W.; Jiang, Y.; Xue, Q.; Sun, F.; Zhang, J.; Zhou, J.; Niu, Z.; Li, Q.; Li, F.; Shen, T. Structural characterisation and immunomodulatory activity of a polysaccharide isolated from lotus (Nelumbo nucifera Gaertn.) root residues. J. Funct. Foods 2019, 60, 103457. [CrossRef]

5. Zhu, Z.; Li, S.; He, J.; Thirumdas, R.; Montesano, D.; Barba, F.J. Enzyme-assisted extraction of polyphenol from edible lotus (Nelumbo nucifera) rhizome knot: Ultra-filtration performance and HPLC-MS2 profile. Food Res. Int. 2018, 111, 291-298. [CrossRef]

6. Chen, G.-L.; Fan, M.-X.; Wu, J.-L.; Li, N.; Guo, M.-Q. Antioxidant and anti-inflammatory properties of flavonoids from lotus plumule. Food Chem. 2019, 277, 706-712. [CrossRef]

7. Lin, S.; Wang, Z.; Lin, Y.; Ge, S.; Hamzah, S.S.; Hu, J. Bound phenolics from fresh lotus seeds exert anti-obesity effects in 3T3-L1 adipocytes and high-fat diet-fed mice by activation of AMPK. J. Funct. Foods 2019, 58, 74-84. [CrossRef]

8. Yi, Y.; Huang, X.-Y.; Zhong, Z.-T.; Huang, F.; Li, S.-Y.; Wang, L.-M.; Min, T.; Wang, H.-X. Structural and biological properties of polysaccharides from lotus root. Int. J. Biol. Macromol. 2019, 130, 454-461. [CrossRef]

9. Huang, B.; Ban, X.; He, J.; Tong, J.; Tian, J.; Wang, Y. Hepatoprotective and antioxidant activity of ethanolic extracts of edible lotus (Nelumbo nucifera Gaertn.) leaves. Food Chem. 2010, 120, 873-878. [CrossRef]

10. Li, F.; Sun, X.-Y.; Li, X.-W.; Yang, T.; Qi, L.-W. Enrichment and separation of quercetin-3-O- $\beta$-D-glucuronide from lotus leaves (nelumbo nucifera gaertn.) and evaluation of its anti-inflammatory effect. J. Chromatogr. $B$ 2017, 1040, 186-191. [CrossRef]

11. Song, Y.-R.; Han, A.-R.; Lim, T.-G.; Lee, E.-J.; Hong, H.-D. Isolation, purification, and characterization of novel polysaccharides from lotus (Nelumbo nucifera) leaves and their immunostimulatory effects. Int. J. Biol. Macromol. 2019, 128, 546-555. [CrossRef] [PubMed]

12. Ahn, J.H.; Kim, E.S.; Lee, C.; Kim, S.; Cho, S.-H.; Hwang, B.Y.; Lee, M.K. Chemical constituents from Nelumbo nucifera leaves and their anti-obesity effects. Bioorganic Med. Chem. Lett. 2013, 23, 3604-3608. [CrossRef] [PubMed]

13. Huang, H.; Belwal, T.; Jiang, L.; Hu, J.; Limwachiranon, J.; Li, L.; Ren, G.; Zhang, X.; Luo, Z. Valorization of lotus byproduct (Receptaculum Nelumbinis) under green extraction condition. Food Bioprod. Process. 2019, 115, 110-117. [CrossRef]

14. Kim, M.-J.; Shin, H.-S. Antioxidative effect of lotus seed and seedpod extracts. Food Sci. Biotechnol. 2012, 21, 1761-1766. [CrossRef]

15. Xu, J.; Rong, S.; Xie, B.; Sun, Z.; Zhang, L.; Wu, H.; Yao, P.; Hao, L.; Liu, L. Procyanidins Extracted From the Lotus Seedpod Ameliorate Age-Related Antioxidant Deficit in Aged Rats. J. Gerontol.: Ser. A 2010, 65A, 236-241. [CrossRef]

16. Qi, S.; Zhou, D. Lotus seed epicarp extract as potential antioxidant and anti-obesity additive in Chinese Cantonese Sausage. Meat Sci. 2013, 93, 257-262. [CrossRef]

17. Liu, Y.; Ma, S.-s.; Ibrahim, S.A.; Li, E.-h.; Yang, H.; Huang, W. Identification and antioxidant properties of polyphenols in lotus seed epicarp at different ripening stages. Food Chem. 2015, 185, 159-164. [CrossRef]

18. Liu, Y.; Hui, X.; Ibrahim, A.S.; Huang, W. Increasing Antiradical Activity of Polyphenols from Lotus Seed Epicarp by Probiotic Bacteria Bioconversion. Molecules 2018, 23, 2667. [CrossRef]

19. Yan, Z.; Luo, X.; Cong, J.; Zhang, H.; Ma, H.; Duan, Y. Subcritical water extraction, identification and antiproliferation ability on HepG2 of polyphenols from lotus seed epicarp. Ind. Crop. Prod. 2019, 129, 472-479. [CrossRef] 
20. Corinti, D.; Maccelli, A.; Crestoni, M.E.; Cesa, S.; Quaglio, D.; Botta, B.; Ingallina, C.; Mannina, L.; Tintaru, A.; Chiavarino, B.; et al. IR ion spectroscopy in a combined approach with MS/MS and IM-MS to discriminate epimeric anthocyanin glycosides (cyanidin 3-O-glucoside and -galactoside). Int. J. Mass Spectrom. 2019, 444, 116179. [CrossRef]

21. Tian, Q.; Giusti, M.M.; Stoner, G.D.; Schwartz, S.J. Screening for anthocyanins using high-performance liquid chromatography coupled to electrospray ionization tandem mass spectrometry with precursor-ion analysis, product-ion analysis, common-neutral-loss analysis, and selected reaction monitoring. J. Chromatogr. A 2005, 1091, 72-82. [CrossRef] [PubMed]

22. Sáez, V.; Gayoso, C.; Riquelme, S.; Pérez, J.; Vergara, C.; Mardones, C.; von Baer, D. C18 core-shell column with in-series absorbance and fluorescence detection for simultaneous monitoring of changes in stilbenoid and proanthocyanidin concentrations during grape cane storage. J. Chromatogr. B 2018, 1074-1075, 70-78.

23. Lijia, X.; Guo, J.; Chen, Q.; Baoping, J.; Zhang, W. Quantitation of phlorizin and phloretin using an ultra high performance liquid chromatography-electrospray ionization tandem mass spectrometric method. J. Chromatogr. B 2014, 960, 67-72. [CrossRef] [PubMed]

24. Friedrich, W.; Eberhardt, A.; Galensa, R. Investigation of proanthocyanidins by HPLC with electrospray ionization mass spectrometry. Eur. Food Res. Technol. 2000, 211, 56-64. [CrossRef]

25. Gangopadhyay, N.; Rai, D.K.; Brunton, N.P.; Gallagher, E.; Hossain, M.B. Antioxidant-guided isolation and mass spectrometric identification of the major polyphenols in barley (Hordeum vulgare) grain. Food Chem. 2016, 210, 212-220. [CrossRef]

26. Teleszko, M.; Nowicka, P.; Wojdyło, A. Effect of cultivar and storage temperature on identification and stability of polyphenols in strawberry cloudy juices. J. Food Compos. Anal. 2016, 54, 10-19. [CrossRef]

27. Nowicka, A.; Kucharska, A.Z.; Sokół-Łętowska, A.; Fecka, I. Comparison of polyphenol content and antioxidant capacity of strawberry fruit from 90 cultivars of Fragaria $\times$ ananassa Duch. Food Chem. 2019, 270, 32-46. [CrossRef]

28. Hu, K.; Dars, A.G.; Liu, Q.; Xie, B.; Sun, Z. Phytochemical profiling of the ripening of Chinese mango (Mangifera indica L.) cultivars by real-time monitoring using UPLC-ESI-QTOF-MS and its potential benefits as prebiotic ingredients. Food Chem. 2018, 256, 171-180. [CrossRef]

29. Zhang, D.-Y.; Wan, Y.; Hao, J.-Y.; Hu, R.-Z.; Chen, C.; Yao, X.-H.; Zhao, W.-G.; Liu, Z.-Y.; Li, L. Evaluation of the alkaloid, polyphenols, and antioxidant contents of various mulberry cultivars from different planting areas in eastern China. Ind. Crop. Prod. 2018, 122, 298-307. [CrossRef]

30. Wootton-Beard, P.C.; Moran, A.; Ryan, L. Stability of the total antioxidant capacity and total polyphenol content of 23 commercially available vegetable juices before and after in vitro digestion measured by FRAP, DPPH, ABTS and Folin-Ciocalteu methods. Food Res. Int. 2011, 44, 217-224. [CrossRef]

31. Samsonowicz, M.; Regulska, E.; Karpowicz, D.; Leśniewska, B. Antioxidant properties of coffee substitutes rich in polyphenols and minerals. Food Chem. 2019, 278, 101-109. [CrossRef] [PubMed]

32. Menghini, L.; Leporini, L.; Vecchiotti, G.; Locatelli, M.; Carradori, S.; Ferrante, C.; Zengin, G.; Recinella, L.; Chiavaroli, A.; Leone, S.; et al. stigmas and byproducts: Qualitative fingerprint, antioxidant potentials and enzyme inhibitory activities. Food Res. Int. 2018, 109, 91-98. [CrossRef] [PubMed]

33. Xi, L.; Mu, T.; Sun, H. Preparative purification of polyphenols from sweet potato (Ipomoea batatas L.) leaves by AB-8 macroporous resins. Food Chem. 2015, 172, 166-174. [CrossRef]

34. Zhou, P.; Zhang, L.; Li, W.; Zhang, S.; Luo, L.; Wang, J.; Sun, B. In vitro evaluation of the anti-digestion and antioxidant effects of grape seed procyanidins according to their degrees of polymerization. J. Funct. Foods 2018, 49, 85-95. [CrossRef]

35. Muñoz-Labrador, A.; Prodanov, M.; Villamiel, M. Effects of high intensity ultrasound on disaggregation of a macromolecular procyanidin-rich fraction from Vitis vinifera L. seed extract and evaluation of its antioxidant activity. Ultrason. Sonochemistry 2019, 50, 74-81. [CrossRef]

36. Chen, X.-M.; Ma, Z.; Kitts, D.D. Effects of processing method and age of leaves on phytochemical profiles and bioactivity of coffee leaves. Food Chem. 2018, 249, 143-153. [CrossRef]

37. Mohd Hazli, U.H.A.; Abdul-Aziz, A.; Mat-Junit, S.; Chee, C.F.; Kong, K.W. Solid-liquid extraction of bioactive compounds with antioxidant potential from Alternanthera sesillis (red) and identification of the polyphenols using UHPLC-QqQ-MS/MS. Food Res. Int. 2019, 115, 241-250. [CrossRef] 
38. Benzie, I.F.F.; Strain, J.J. The Ferric Reducing Ability of Plasma (FRAP) as a Measure of "Antioxidant Power": The FRAP Assay. Anal. Biochem. 1996, 239, 70-76. [CrossRef]

Sample Availability: Samples of the compounds LSEP are available from the authors. 